\title{
A case of IgG4-related kidney disease with predominantly unilateral renal atrophy
}

\author{
Akari Takeji ${ }^{1}$ Kazunori Yamada ${ }^{1,2} \cdot$ Dai Inoue $^{3} \cdot$ Ichiro Mizushima $^{1} \cdot$ Satoshi Hara ${ }^{1} \cdot$ Kiyoaki Ito $^{1} \cdot$ Hiroshi Fujii ${ }^{1}$. \\ Kenichi Nakajima ${ }^{4} \cdot K$ azuaki Mizutomi ${ }^{5} \cdot$ Masakazu Yamagishi $^{6} \cdot$ Mitsuhiro Kawano $^{1}$
}

Received: 24 March 2018 / Accepted: 23 July 2018 / Published online: 30 July 2018

(C) The Author(s) 2018

\begin{abstract}
A 73-year-old Japanese woman was diagnosed with type 1 autoimmune pancreatitis (AIP) without kidney lesions. She was treated with prednisolone (PSL) $30 \mathrm{mg} / \mathrm{day}$, and her AIP symptoms promptly improved, after which the PSL dose was gradually tapered to $5 \mathrm{mg} / \mathrm{day}$. Her renal function had remained normal (serum creatinine $0.7 \mathrm{mg} / \mathrm{dL}$ ) until 1 year before the current admission without any imaging abnormalities in the kidney. However, during this past year her renal function gradually declined (serum creatinine $1.1 \mathrm{mg} / \mathrm{dL}$ ). Follow-up computed tomography incidentally revealed unilateral renal atrophy, which rapidly progressed during the subsequent 10-month period without left kidney atrophy. A diagnosis of IgG4RKD probably due to TIN was made, and we increased the dose of prednisolone to $30 \mathrm{mg} /$ day. 1 month after administration, multiple low-density lesions on both kidneys were improved slightly but almost all lesions persisted as atrophic scars. Our case suggested that unilateral renal atrophy can develop in patients with IgG4-related tubulointerstitial nephritis without hydronephrosis caused by retroperitoneal fibrosis, and that monitoring the serum creatinine levels is not always sufficient, thereby highlighting the importance of regular imaging monitoring to detect newly developing kidney lesions.
\end{abstract}

Keywords IgG4-related disease $\cdot$ IgG4-related kidney disease $\cdot$ Tubulointerstitial nephritis $\cdot$ Unilateral renal atrophy

\section{Introduction}

IgG4-related disease (IgG4-RD) is a systemic inflammatory disease characterized by an elevated serum IgG4 level, IgG4-positive plasma cell infiltration, and fibrosis in

Mitsuhiro Kawano

sk33166@gmail.com

1 Division of Rheumatology, Kanazawa University Hospital, Kanazawa University Graduate School of Medicine, 13-1, Takara-machi, Kanazawa, Ishikawa 920-8640, Japan

2 Department of Advanced Research in Community Medicine, Kanazawa University Graduate School of Medical Sciences, Kanazawa, Ishikawa, Japan

3 Department of Radiology, Kanazawa University Graduate School of Medical Science, Kanazawa, Ishikawa, Japan

4 Department of Nuclear Medicine, Kanazawa University Hospital, Kanazawa, Ishikawa, Japan

5 Internal Medicine, Kaga Medical Center, Kaga, Ishikawa, Japan

6 Division of Cardiology, Kanazawa University Graduate School of Medicine, Kanazawa, Ishikawa, Japan affected organs, which is becoming increasingly well recognized [1-5]. Patients with IgG4-related kidney disease (IgG4-RKD) reveal various renal abnormalities on imaging studies, such as multiple low-density lesions on contrastenhanced computed tomography (CE-CT), diffuse bilateral renal swelling, and/or a hypovascular solitary nodule [6, 7], resulting in partial or diffuse renal atrophy in some cases $[8$, 9]. However, unilateral renal atrophy is very rare except in cases of unilateral hydronephrosis caused by IgG4-related retroperitoneal fibrosis $[10,11]$. Here, we describe a patient with IgG4-RKD manifesting predominantly unilateral renal atrophy probably due to IgG4-related tubulointerstitial nephritis (IgG4-related TIN).

\section{Case report}

A 73-year-old woman was admitted to our hospital for close examination of gradually decreasing renal function. She was first referred to our hospital with obstructive jaundice due to a pancreatic head mass 6 years earlier (Fig. 1). CE-CT showed focal enlargement of the pancreas. 


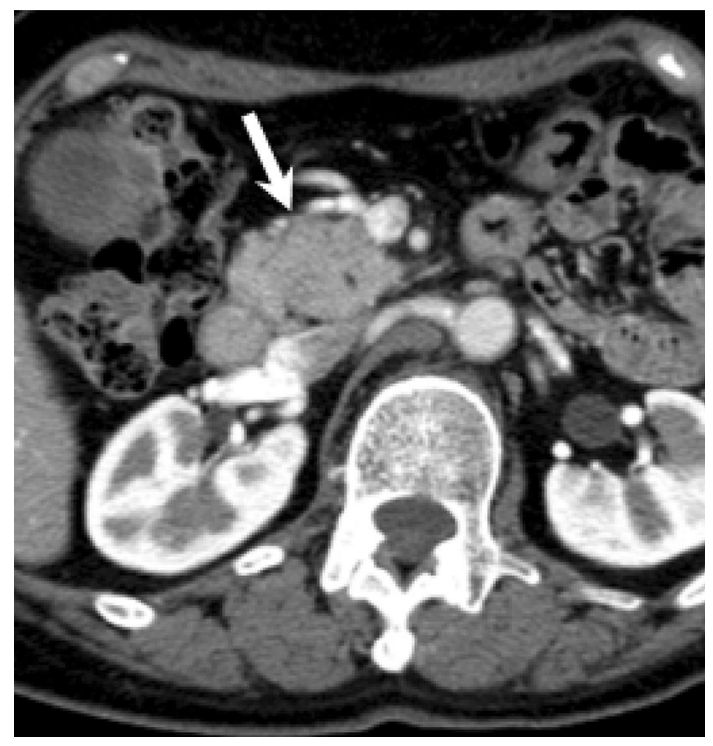

Fig. 1 Contrast-enhanced computed tomography (CE-CT) findings at diagnosis of IgG4-related disease. CE-CT revealed a mass in the pancreatic head when she was first referred to our hospital with obstructive jaundice 6 years earlier

Endoscopic retrograde pancreatography showed irregular narrowing of the main pancreatic duct. After closer examinations, type 1 autoimmune pancreatitis (AIP) was highly suspected because she had an elevated serum IgG4 level $(378 \mathrm{mg} / \mathrm{dL})$, which exceeded by more than twofold the upper limit of the normal range. She was treated with prednisolone (PSL) $30 \mathrm{mg} /$ day, after which her symptoms promptly improved with serum IgG4 level decreased $(165 \mathrm{mg} / \mathrm{dL})$. Finally, a definite diagnosis of type 1 AIP was made based on the Clinical Diagnostic Criteria for Autoimmune Pancreatitis 2011 (level 1 serology and diagnostic steroid trial) [12]. The PSL dose was gradually tapered to $5 \mathrm{mg} /$ day. Before starting treatment, no other characteristic lesions of IgG4-RD commonly found in the kidney or lacrimal and salivary gland were present (Fig. 3a, c). She had a history of hypertension, hyperlipidemia, paroxysmal atrial fibrillation, and old cerebral infarction. Her renal function had remained normal (serum creatinine $0.7 \mathrm{mg} / \mathrm{dL}$ ) until 1 year before the current admission without any imaging abnormalities in the kidney. However, during this past year her renal function gradually declined (serum creatinine $1.1 \mathrm{mg} / \mathrm{dL}$ ) and follow-up CT revealed right dominant renal atrophy (Fig. 2). On admission, she was afebrile and her consciousness was clear. On physical examination, blood pressure was $99 / 54 \mathrm{mmHg}$ and pulse 67 beats per minute. There were no remarkable findings except for slightly swollen bilateral lacrimal glands. Pitting edema on the lower extremities was seen. Laboratory findings (Table 1) included CRP $0.1 \mathrm{mg} / \mathrm{dL}$, creatinine (Cr) $0.88 \mathrm{mg} / \mathrm{dL}$ (eGFR $48.1 \mathrm{~mL} / \mathrm{min} / 1.73 \mathrm{~m}^{2}$ ), BUN 17 mg/dL, IgG 1261 mg/dL, IgG4 $201 \mathrm{mg} / \mathrm{dL}$ (IgG4/ IgG: 16\%), IgA $276 \mathrm{mg} / \mathrm{dL}$, IgM $160 \mathrm{mg} / \mathrm{dL}$, IgE $1025 \mathrm{IU} /$ $\mathrm{mL}, \mathrm{C} 3108 \mathrm{mg} / \mathrm{dL}, \mathrm{C} 423 \mathrm{mg} / \mathrm{dL}$, and CH50 $60 \mathrm{U} / \mathrm{mL}$. Rheumatoid factor, anti-nuclear antibodies, anti-SSA antibodies, anti-myeloperoxidase anti-neutrophil cytoplasmic antibodies (ANCA), and anti-proteinase 3 ANCA were all negative. Neither proteinuria nor hematuria was present. The level of urinary $N$-acetyl- $\beta$-D-glucosaminidase (NAG) was $1.9 \mathrm{IU} / \mathrm{L}$ and that of urinary $\beta 2$-microglobulin ( $\beta 2$ MG) was $<75 \mu \mathrm{g} / \mathrm{L}$. Ga-scintigraphy showed no uptake on kidneys, pancreas, salivary glands, or lymph node. CE-CT on admission demonstrated multiple low-density lesions in the bilateral kidneys that led us consider the possibility of IgG4-RKD. Renal atrophy was seen predominantly in the right kidney (Fig. 3b, d). Renal Technetium-99m diethylene triamine pentaacetic acid (Tc-99m DTPA) scintigraphy revealed marked right renal dysfunction (GFR: left $40.6 \mathrm{~mL} / \mathrm{min}$, right $10.6 \mathrm{~mL} / \mathrm{min}$; Fig. 4).

We decided not to perform a renal biopsy because of the right renal atrophy and malformation of the left renal vein in the inferior pole of the left kidney. We performed renal artery ultrasound. Right and left peak systolic velocity (PSV) was 92 and $64 \mathrm{~cm} / \mathrm{s}$, respectively, and renal aortic ratio (RAR) was 1.0 and 0.7 , respectively. These data supported the absence of renal artery stenosis. D-Dimer levels were not elevated $(0.9 \mu \mathrm{g} / \mathrm{mL}$ : normal $<1.0)$ on admission. Moreover, D-dimer levels were constantly within the
Fig. 2 Plain CT images 10 months before (a) and on admission (b). The right renal parenchymal atrophy showed rapid progression during the 10-month period
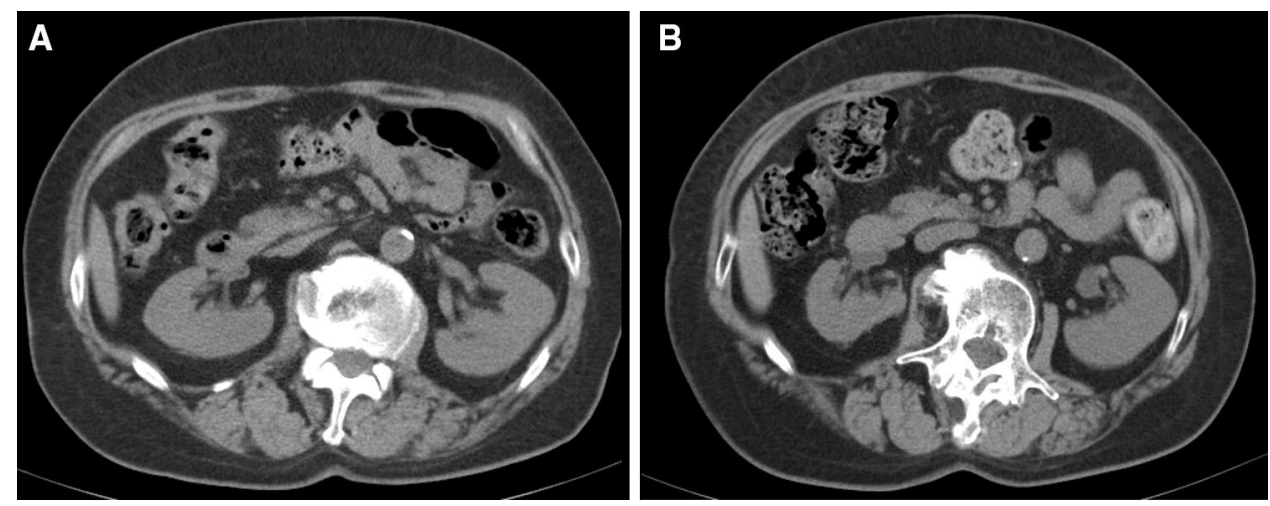
Fig. 3 CE-CT images before glucocorticoid therapy for type 1 autoimmune pancreatitis (a, c) and on admission (b, d). CE-CT on admission revealed multiple low-density lesions in the bilateral kidneys and marked atrophy limited to the right kidney. The left kidney showed only partial atrophy $(\mathbf{b}, \mathbf{d})$
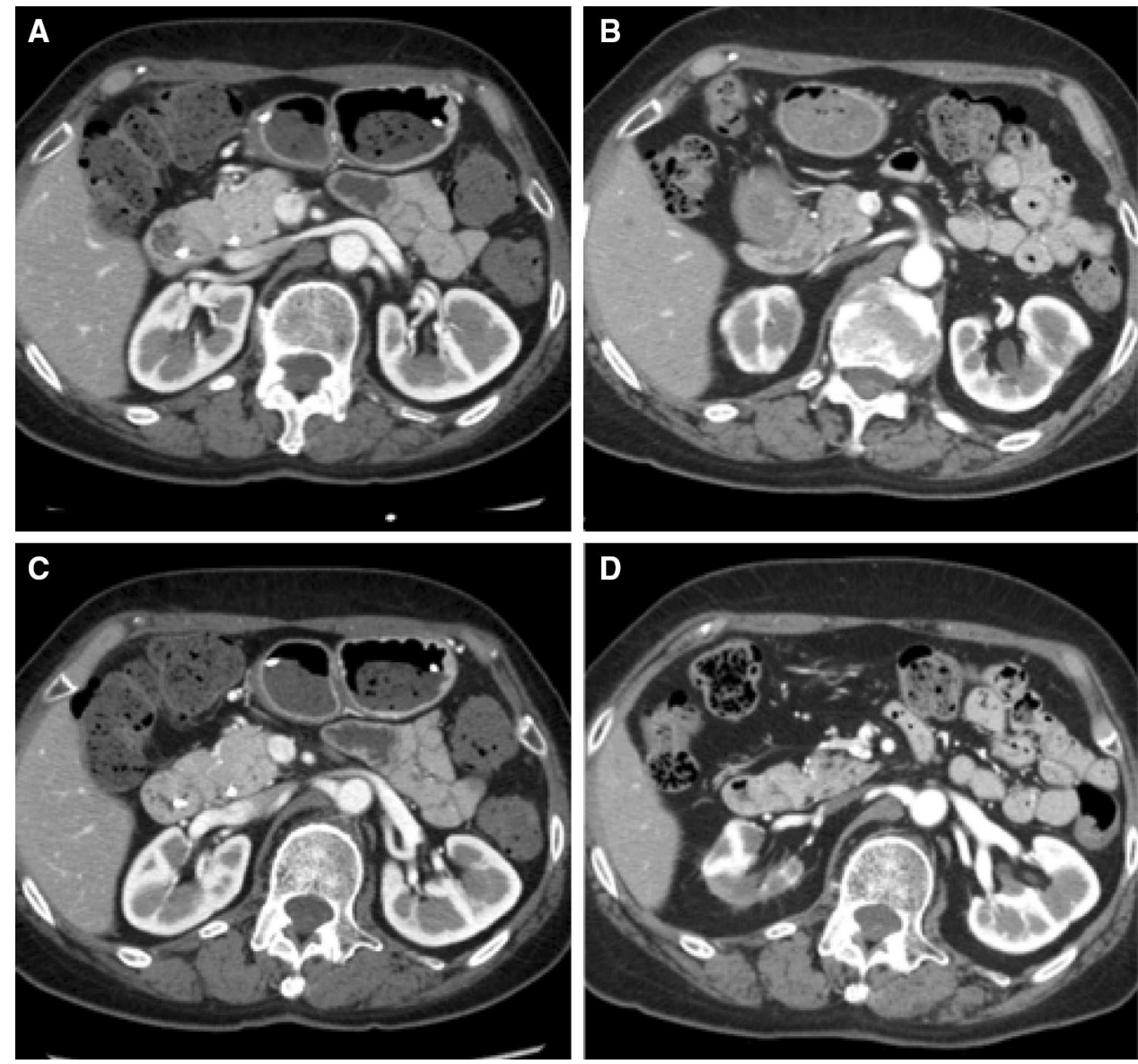

normal range throughout the clinical course. Therefore, thrombotic event of the right kidney was also ruled out.

Based on the results of extensive examinations such as chest X-ray, echocardiograph, ultrasound, and gallium scintigraphy, we differentiated IgG4-RKD from other vascular diseases such as renal arterial stenosis, thromboembolism, and aneurysm. Finally, a diagnosis of IgG4-RKD probably due to TIN was made, and we increased the dose of prednisolone to $30 \mathrm{mg} /$ day. 1 month after increasing the dose of corticosteroid, the left kidney lesions showing multiple low-density lesions and mild partial atrophy demonstrated almost no change (Fig. 5).

3 months after increasing the dose of corticosteroid, the patient was treated with a maintenance dose of $14 \mathrm{mg} /$ day of prednisolone, and renal function was stable (Fig. 6).

\section{Discussion}

We experienced a case of IgG4-RKD with predominantly unilateral renal atrophy without retroperitoneal fibrosis. This case had a very unusual clinical course. At onset, she showed only a pancreatic lesion, with diagnostic imaging not revealing any kidney lesions. Follow-up CT performed during the maintenance therapy did not detect any newly developed renal lesions either until unilateral renal atrophy was detected incidentally and showed rapid progression during the following 10-month period despite the left kidney remaining almost normal.

A characteristic imaging finding of IgG4-RKD is multiple low-density lesions on CE-CT, with almost all cases having bilateral lesions [6, 7]. However, a few reports have rarely described IgG4-RKD with a single mass lesion [13, 14]. In general, rapid unilateral renal atrophy is caused by renal arterial stenosis, renal infarction, thromboembolism, or hydronephrosis associated with periaortitis or inflammatory abdominal aortic aneurysm [15, 16]. Moreover, unilateral renal atrophy could be induced by unilateral hydronephrosis in cases with IgG4-related periaortitis/retroperitoneal fibrosis $[10,11]$. However, this is the first reported case with IgG4-RKD to show multiple low-density lesions in the bilateral kidneys on CE-CT and obvious unilateral renal atrophy without retroperitoneal fibrosis or hydronephrosis.

This case highlights the difficulty of knowing when best, or if at all, to start glucocorticoid therapy in patients with IgG4-related TIN [17]. In other words, whether careful watching without therapy is acceptable or not in patients with IgG4-related TIN with preserved renal 
Table 1 Laboratory data of the present case on admission to our hospital

\begin{tabular}{|c|c|c|}
\hline & Value & Normal range \\
\hline \multicolumn{3}{|l|}{ Urinalysis } \\
\hline Protein & - & - \\
\hline Occult blood & - & - \\
\hline Sugar & - & - \\
\hline G. cast & - & - \\
\hline Urinary beta 2 microglobulin $(\mathrm{ng} / \mathrm{mL})$ & $<75$ & \\
\hline $\begin{array}{l}\text { Urinary } N \text {-acetyl-beta-D-glucosaminidase } \\
\text { (IU/L) }\end{array}$ & 1.9 & \\
\hline \multicolumn{3}{|l|}{ Blood count } \\
\hline White blood cells $(/ \mu \mathrm{L})$ & 6050 & $3300-8800$ \\
\hline Eo $(\%)$ & 1.2 & $0-6$ \\
\hline $\mathrm{RBC}(/ \mu \mathrm{L})$ & 368 & $430-550$ \\
\hline $\mathrm{Hb}(\mathrm{g} / \mathrm{dL})$ & 11.7 & $13.5-17.0$ \\
\hline Plt $(/ \mu \mathrm{L})$ & 24.4 & $13.0-35.0$ \\
\hline $\operatorname{ESR}(\mathrm{mm} / \mathrm{h})$ & 47 & \\
\hline \multicolumn{3}{|l|}{ Serum chemistry } \\
\hline BUN (mg/dL) & 17 & $8-22$ \\
\hline $\mathrm{Cr}(\mathrm{mg} / \mathrm{dL})$ & 0.88 & $0.60-1.00$ \\
\hline $\mathrm{UA}(\mathrm{mg} / \mathrm{dL})$ & 4.5 & $3.6-7.0$ \\
\hline $\mathrm{Na}(\mathrm{mEq} / \mathrm{L})$ & 146 & $135-149$ \\
\hline $\mathrm{K}(\mathrm{mEq} / \mathrm{L})$ & 4.2 & $3.5-4.9$ \\
\hline $\mathrm{Cl}(\mathrm{mEq} / \mathrm{L})$ & 107 & $96-108$ \\
\hline $\operatorname{ALP}(\mathrm{IU} / \mathrm{L})$ & 144 & $115-359$ \\
\hline$\gamma \mathrm{GTP}(\mathrm{IU} / \mathrm{L})$ & 19 & $10-47$ \\
\hline AST (IU/L) & 20 & $13-33$ \\
\hline ALT (IU/L) & 15 & $8-42$ \\
\hline LDH (IU/L) & 249 & $119-229$ \\
\hline Amy (IU/L) & 119 & $4-113$ \\
\hline $\mathrm{TP}(\mathrm{g} / \mathrm{dL})$ & 7.1 & $6.7-8.3$ \\
\hline Alb (g/dL) & 3.9 & $4.0-5.0$ \\
\hline HbA1c (\%) & 6.2 & $4.3-5.8$ \\
\hline FDP-DD $(\mu \mathrm{g} / \mathrm{mL})$ & 0.9 & $<1.0$ \\
\hline \multicolumn{3}{|l|}{ Immunological findings } \\
\hline $\mathrm{CRP}(\mathrm{mg} / \mathrm{dL})$ & 0.1 & $0.0-0.3$ \\
\hline $\operatorname{IgG}(\mathrm{mg} / \mathrm{dL})$ & 1261 & $870-1700$ \\
\hline IgG4 (mg/dL) & 201 & $<135$ \\
\hline $\operatorname{Ig} \mathrm{A}(\mathrm{mg} / \mathrm{dL})$ & 276 & $110-410$ \\
\hline $\operatorname{IgM}(\mathrm{mg} / \mathrm{dL})$ & 160 & $33-190$ \\
\hline $\operatorname{IgE}(\mathrm{IU} / \mathrm{mL})$ & 1025 & $<250$ \\
\hline CH50 (U/mL) & 60 & $32-47$ \\
\hline $\mathrm{C} 3(\mathrm{mg} / \mathrm{dL})$ & 108 & $65-135$ \\
\hline $\mathrm{C} 4(\mathrm{mg} / \mathrm{dL})$ & 23 & $13-35$ \\
\hline Anti-nuclear antibody & $<\times 40$ & - \\
\hline $\mathrm{RF}(\mathrm{IU} / \mathrm{mL})$ & 4.5 & $<20$ \\
\hline
\end{tabular}

$R B C$ red blood cell, $H b$ hemoglobin, Plt platelets, $B U N$ blood urea nitrogen, $C r$ creatinine, $U A$ uric acid, $A L P$ alkaline phosphatase, $\gamma$ GTP g-glutamyltransferase, $A S T$ aspartate aminotransferase, $A L T$ alanine aminotransferase, $L D H$ lactate dehydrogenase, $C R P$ C-reactive protein, $R F$ rheumatoid factor
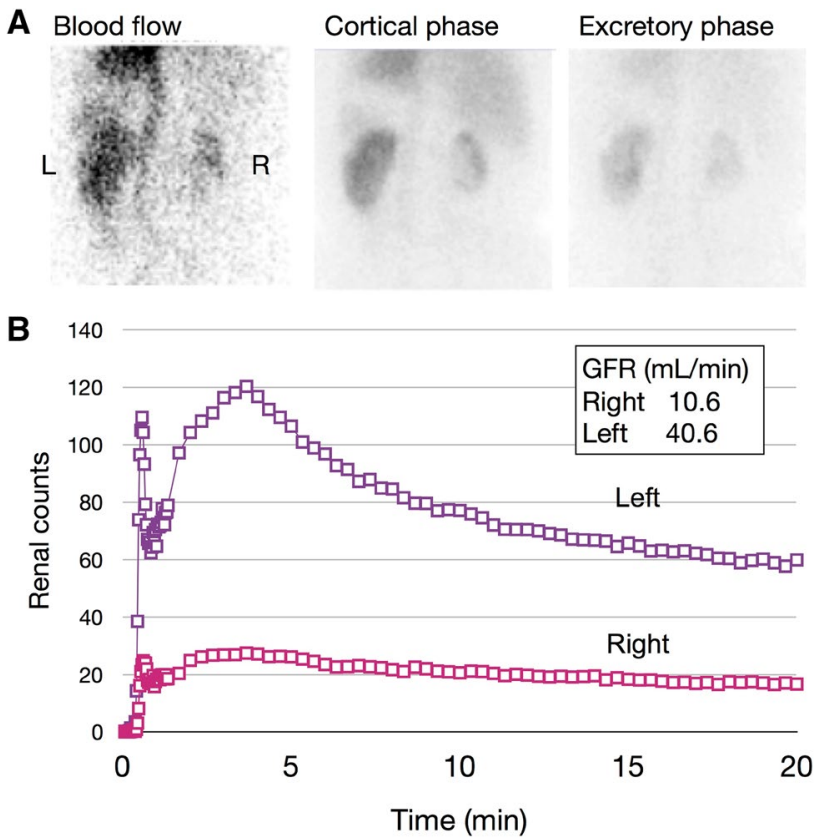

Fig. 4 Tc-99m DTPA scintigraphy. Estimated glomerular filtration rate (eGFR) of left kidney was $40.6 \mathrm{~mL} / \mathrm{min}$ and of right kidney was $10.6 \mathrm{~mL} / \mathrm{min}$. Right renal dysfunction was remarkable

function is still unanswered. Raissian et al. analyzed the clinical course of 27 patients with IgG4-related TIN with or without glucocorticoid therapy with a mean follow-up time of 14.5 months (range 1-84 months) [18]. In their report, 5 of 27 patients were followed without steroid, of whom two developed elevation of serum creatinine $(\mathrm{Cr})$ levels from around $1.0-1.8 \mathrm{mg} / \mathrm{dL}$ while the remaining 3 patients did not despite already showing moderate renal dysfunction. Of 22 of 27 patients receiving corticosteroid therapy, most including those with markedly increased serum Cr levels responded well to the steroid. Saeki et al. reported that all 43 patients with IgG4-related TIN who were treated with steroid achieved stabilization or improvement of renal function, improvement of radiological findings, and resolution of extra-renal manifestations at 1 month after starting therapy [17]. In contrast, Horita et al. described a patient with IgG4-related TIN in whom the morphological findings of multiple low-density lesions dramatically changed into diffuse patchy lesions and the serum creatinine level increased from 0.70 to $1.30 \mathrm{mg} / \mathrm{dL}$ during a 5-month interval without corticosteroid therapy [19]. The experience with such reported cases suggests that corticosteroid administration should be immediately initiated in cases with IgG4-related TIN. In our case, the renal function decreased slowly while the renal atrophy progressed rapidly. This implies that careful serum $\mathrm{Cr}$ level monitoring is not sufficient to detect rapid renal damage in patients with IgG4-RD as soon as possible, meaning 
Fig. 5 Contrast-enhanced computed tomography images on admission $(\mathbf{a}, \mathbf{c})$ and 1 month after glucocorticoid therapy (b, d). After steroid therapy, the left kidney lesions showing low density and mild partial atrophy demonstrated almost no change
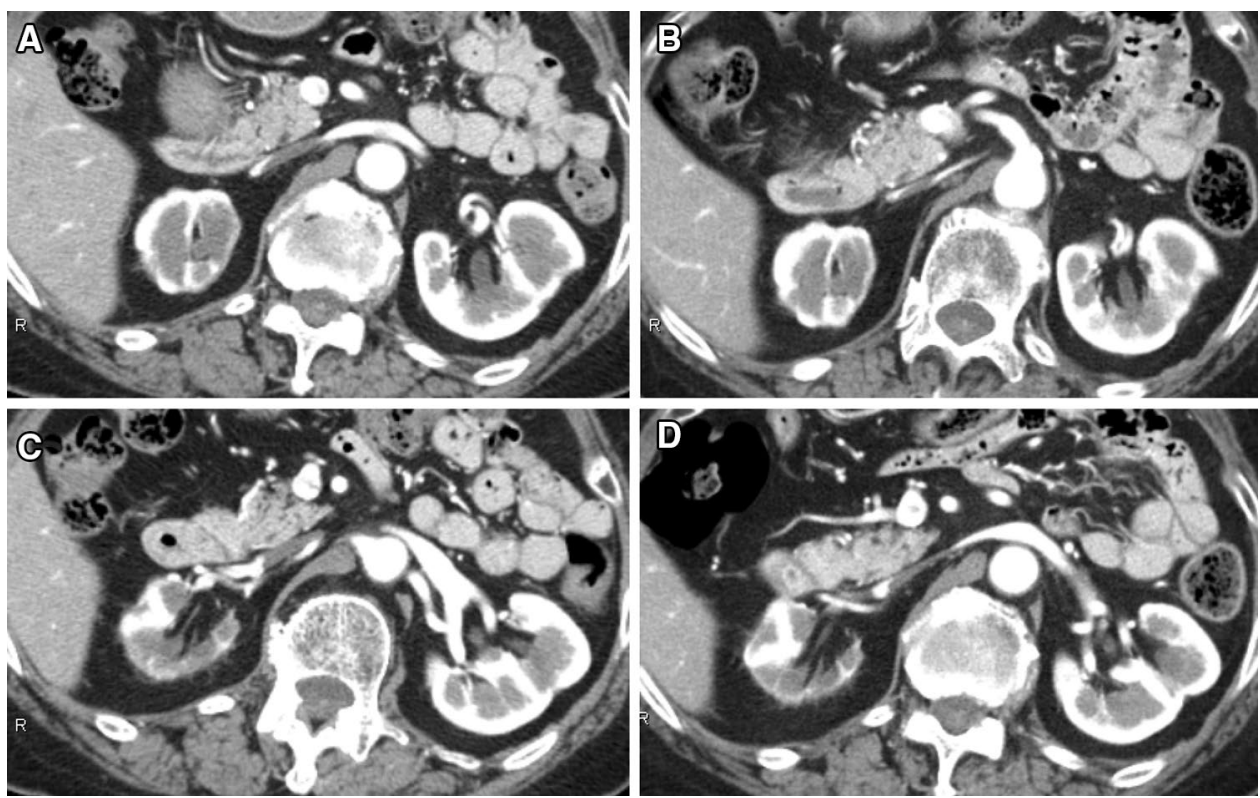

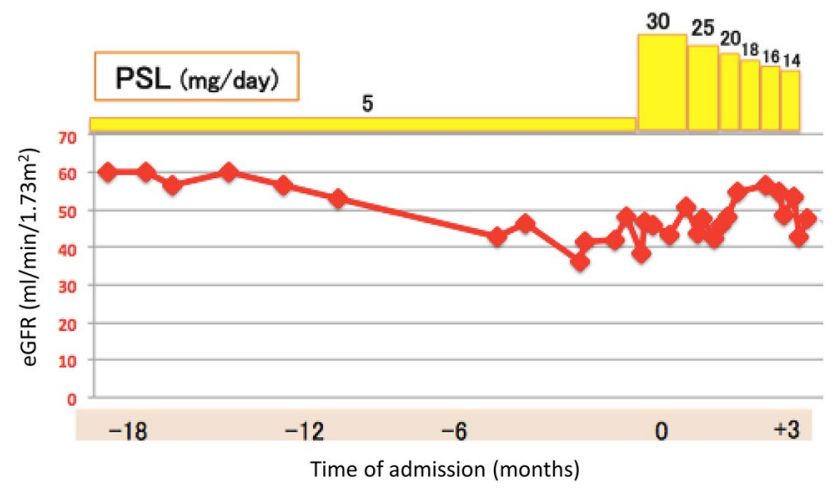

Fig. 6 Time course of estimated glomerular filtration rate (eGFR) and prednisolone (PSL) administration. 1 month after increasing the dose of PSL from 5 to $30 \mathrm{mg} /$ day, her renal function improved, and subsequently remained stable. From 3 months after increasing the dose of corticosteroid, the patient has been treated with a maintenance dose of $14 \mathrm{mg} /$ day of prednisolone

that early treatment would be desirable for IgG4-related TIN patients even if the deterioration rate of renal function is slow.

In our case, urine levels of NAG and $\beta 2-\mathrm{MG}$ were not elevated. Mizushima et al. described 6 patients with IgG4related TIN. In their report, urine $\beta 2-\mathrm{MG}$ excretion was not elevated in one patient (16.7\%) nor urine NAG level in four $(66.7 \%)$. Also, urine $\beta 2-\mathrm{MG}$ and NAG concentrations fluctuated despite the corticosteroid therapy [20]. Furthermore, Nishi et al. reported elevations of urine NAG and $\alpha 1-\mathrm{MG}$ levels in 78.6 and $30.8 \%$ of the patients, respectively [21]. These findings draw attention to the fact that tubulointerstitial markers are not necessarily elevated in IgG4-related TIN patients.
The present case raises the interesting question of why only the left kidney showed very mild atrophy. In this case, lesions involved the right renal cortex diffusely culminating in severe diffuse atrophy. On the other hand, kidney lesions were limited to only a part of the left cortex, with this being the reason why most of the left kidney was spared severe atrophy (only partial atrophy). We assume that the difference in the degree of atrophy was largely attributable to such difference in the extent of renal involvement (severe in the right, in contrast to only partial in the left).

In conclusion, we experienced a case of IgG4-RKD with predominantly unilateral renal atrophy probably due to newly developed IgG4-related TIN during the clinical course of type 1 AIP with maintenance corticosteroid therapy. The course of this case suggests that monitoring the serum $\mathrm{Cr}$ levels is not always sufficient, thereby highlighting the importance of regular imaging monitoring to detect newly developing kidney lesions during the clinical course of IgG4-RD with or without maintenance steroid therapy.

Acknowledgements We thank Mr. John Gelblum for his critical reading of the manuscript. This work was supported partially by the Research Program of Intractable Diseases of the Ministry of Health, Labor, and Welfare of Japan, and JSPS KAKENHI Grant number 26461487 and 17K09999.

\section{Compliance with ethical standards}

Conflict of interest All the authors have declared no competing interest.

Human and animal rights This article does not contain any studies with human participants or animals performed by any of the authors. 
Informed consent Informed consent was obtained from all individual participants included in the study.

Open Access This article is distributed under the terms of the Creative Commons Attribution 4.0 International License (http://creativeco mmons.org/licenses/by/4.0/), which permits unrestricted use, distribution, and reproduction in any medium, provided you give appropriate credit to the original author(s) and the source, provide a link to the Creative Commons license, and indicate if changes were made.

\section{References}

1. Stone JH, Zen Y, Deshpande V. IgG4-related disease. N Engl J Med. 2012;366(6):539-51. https://doi.org/10.1056/NEJMra1104 650

2. Umehara H, Okazaki K, Masaki Y, Kawano M, Yamamoto M, Saeki T, et al. A novel clinical entity, IgG4-related disease (IgG4RD): general concept and details. Mod Rheumatol. 2012;22(1):1-14. https://doi.org/10.1007/s10165-011-0508-6.

3. Hamano H, Kawa S, Ochi Y, Unno H, Shiba N, Wajiki M, et al. Hydronephrosis associated with retroperitoneal fibrosis and sclerosing pancreatitis. Lancet. 2002;359(9315):1403-4.

4. Hamano H, Kawa S, Horiuchi A, Unno H, Furuya N, Akamatsu $\mathrm{T}$, et al. High serum IgG4 concentrations in patients with sclerosing pancreatitis. N Engl J Med. 2001;344(10):732-8. https://doi. org/10.1056/NEJM200103083441005.

5. Yamada K, Yamamoto M, Saeki T, Mizushima I, Matsui S, Fujisawa Y, et al. New clues to the nature of immunoglobulin G4-related disease: a retrospective Japanese multicenter study of baseline clinical features of 334 cases. Arthritis Res Ther. 2017;19(1):262. https://doi.org/10.1186/s13075-017-1467-x.

6. Kawano M, Saeki T, Nakashima H, Nishi S, Yamaguchi Y, Hisano S, et al. Proposal for diagnostic criteria for IgG4-related kidney disease. Clin Exp Nephrol. 2011;15(5):615-26. https://doi. org/10.1007/s10157-011-0521-2.

7. Takahashi N, Kawashima A, Fletcher JG, Chari ST. Renal involvement in patients with autoimmune pancreatitis: CT and MR imaging findings. Radiology. 2007;242(3):791-801. https://doi. org/10.1148/radiol.2423060003.

8. Kawano M, Yamada K. IgG4-related kidney disease and IgG4related retroperitoneal fibrosis. Semin Liver Dis. 2016;36(3):28390. https://doi.org/10.1055/s-0036-1584316.

9. Mizushima I, Yamamoto M, Inoue D, Nishi S, Taniguchi Y, Ubara $\mathrm{Y}$, et al. Factors related to renal cortical atrophy development after glucocorticoid therapy in IgG4-related kidney disease: a retrospective multicenter study. Arthritis Res Ther. 2016;18(1):273. https://doi.org/10.1186/s13075-016-1175-y.

10. Hara N, Kawaguchi M, Takeda K, Zen Y. Retroperitoneal disorders associated with IgG4-related autoimmune pancreatitis. World
J Gastroenterol. 2014;20(44):16550-8. https://doi.org/10.3748/ wjg.v20.i44.16550.

11. Lei WH, Xin J, Shao CX, Mao MF, Zhu CY, Wu CF, et al. IgG4-related kidney disease mimicking malignant ureter tumor: case report and literature review. Medicine (Baltimore). 2016;95(3):e2550. https://doi.org/10.1097/MD.000000000000255 0.

12. Shimosegawa T, Chari ST, Frulloni L, Kamisawa T, Kawa S, Mino-Kenudson M, et al. International consensus diagnostic criteria for autoimmune pancreatitis: guidelines of the International Association of Pancreatology. Pancreas. 2011;40(3):352-8. https ://doi.org/10.1097/MPA.0b013e3182142fd2.

13. Bianchi D, Topazio L, Gaziev G, Iacovelli V, Bove P, Mauriello A, et al. IgG4-related kidney disease: report of a case presenting as a renal mass. Case Rep Surg. 2017;2017:9690218. https://doi. org/10.1155/2017/9690218.

14. Shoji S, Nakano M, Usui Y. IgG4-related inflammatory pseudotumor of the kidney. Int J Urol. 2010;17(4):389-90. https://doi. org/10.1111/j.1442-2042.2010.02483.x.

15. Neiman HL, Korsower JM, Reeder MM. Unilateral small kidney. JAMA. 1977;238(9):971-2.

16. Brandt AS, Kamper L, Kukuk S, Haage P, Roth S. Associated findings and complications of retroperitoneal fibrosis in 204 patients: results of a urological registry. J Urol. 2011;185(2):52631. https://doi.org/10.1016/j.juro.2010.09.105.

17. Saeki T, Kawano M, Mizushima I, Yamamoto M, Wada Y, Ubara $\mathrm{Y}$, et al. Recovery of renal function after glucocorticoid therapy for IgG4-related kidney disease with renal dysfunction. Clin Exp Nephrol. 2016;20(1):87-93. https://doi.org/10.1007/s1015 7-015-1140-0.

18. Raissian Y, Nasr SH, Larsen CP, Colvin RB, Smyrk TC, Takahashi $\mathrm{N}$, et al. Diagnosis of IgG4-related tubulointerstitial nephritis. J Am Soc Nephrol. 2011;22(7):1343-52. https://doi.org/10.1681/ ASN.2011010062.

19. Horita S, Fujii H, Mizushima I, Fujisawa Y, Hara S, Yamada K, et al. A case of IgG4-related tubulointerstitial nephritis and membranous glomerulonephritis during the clinical course of gastric cancer: imaging features of IgG4-related kidney disease. Mod Rheumatol. 2016. https://doi.org/10.1080/14397595.2016.12452 38.

20. Mizushima I, Yamada K, Fujii H, Inoue D, Umehara H, Yamagishi $\mathrm{M}$, et al. Clinical and histological changes associated with corticosteroid therapy in IgG4-related tubulointerstitial nephritis. Mod Rheumatol. 2012;22(6):859-70. https://doi.org/10.1007/s1016 5-011-0589-2.

21. Nishi H, Shibagaki Y, Hirano K, Akahane M, Kido R, Nangaku $\mathrm{M}$, et al. Laboratory and imaging features of kidney involvement in autoimmune pancreatitis: incidence, correlation, and steroid therapy response. Clin Nephrol. 2010;73(4):253-9. 